\title{
Experiences and Proposals for Interdisciplinary Engineering Design Courses
}

\author{
Pouyan Jazayeri William (Bill) Rosehart David Westwick \\ Department of Electrical Engineering \\ University of Calgary \\ spjazaye@ucalgary.carrosehart@ucalgary.ca_dwestwic@ucalgary.ca
}

\begin{abstract}
This paper presents some of the experiences gained from the interdisciplinary design course offered at the university of Calgary in the 2004-2005 academic year. It also provides a few proposals and recommendations to improve the course (or similar versions) in the future. The components of the course-lecture content, group structure, design projects, and general course structure - are analyzed and some of the challenges-equal contribution from members, scheduling, grading, and more- are described in this paper. The approaches used in overcoming these problems, along with further suggestions, are also detailed.
\end{abstract}

\section{Introduction}

In fall of 2004, a new capstone design course was offered to $4^{\text {th }}$ year students in Electrical, Computer, Software, Mechanical, and Manufacturing Engineering. Previously restricted to work within their own departments, the students now had the opportunity to work with peers from a different department on a multi-disciplinary project. The design projects were chosen so that (ideally) an equivalent contribution from each of the involved disciplines was required. This course provided an opportunity - and in most cases, the only one-for engineering students at the University of Calgary to work on a project that was not completely restricted to their field of study. The students found the experience to be an invaluable rehearsal for joining the work force. This paper summarizes some of the experiences from this course and provides a few recommendations for future offerings. The remainder of the paper is organized as follows: Section 2 breaks down the components of the course while providing a brief analysis. In Section 3, a concise description of the projects is provided, and Section 4 analyses the group structures. The challenges with scheduling and fairness of grading are discussed in Sections 5 and 6, respectively. Section 7 describes the policies used to ensure equal distribution of work among team members, and Section 8 provides the conclusions and recommendations.

\section{Course content and structure}

This section describes the structure of the course, the activities and assignments that the students were required to perform, along with a brief evaluation of them. This section describes the major elements of the course: lectures, quizzes, reports, design reviews, individual and group presentations and the logbooks used by the groups for record keeping.

2.1 Lectures: The students were taught the basics of project management, public speaking and communications, intellectual property (IP), concept generation and concept selection, risk management, adaptable design, and industrial design. These concepts were selected from a wide variety of sources and perspectives [1-9]. The lectures were made as interactive as possible, and student activities were scattered through the lectures to keep the audience interested. Some of these activities to maintain student interest included: 5-minute group meetings to discuss the topic presented in lecture and apply it to the team project, followed by a discussion with the rest of the class; impromptu presentations by individuals or groups (the topic of the talk could be in any project management filed, as chosen by the instructor); or even unexpected pizza breaks for the class. The students' comments (which accompanied the course evaluations) showed that the students were pleased with the close correlation between the lecture material and their own projects, and in particular with the direct applicability of the concepts discussed in 
class.

2.2 Quizzes: A few unannounced quizzes were handed out throughout the year. The quizzes did not test the students' memorization of the project management theories, but rather asked them to apply those principles to their projects.

2.3 Reports: In the fall semester, the students were required to submit 4 reports: A Background information and Literature Survey Report, 2 update reports, and a final project report. The "background information and literature survey" report was designed to ensure that all project groups resisted the temptation of delaying the start of their work and initiate the process at the beginning of the semester. Each group was required to review at least 5 different sources applicable to their project, and provide a brief description of the major contribution or significance of each reference. The "update reports" were designed to monitor the progress of each group and were required to highlight the design proposals and implementations. The reports were aimed at improving the students' technical communication skills while enabling the instructor to monitor their progress. Since the students felt that the sheer volume of the paperwork was impeding the actual design work, the number of reports was reduced to one for the winter semester.

2.4 Design Reviews: This section of the course provided the students with the opportunity to discuss their designs with one or two other students in the class. The students were encouraged to bring handouts (or any other support material) to these sessions, where they would discuss their design choices and progress with the fellow students. Their ideas were constructively criticized and encouraged, and they would receive practical feedback and new ideas about their project. The enthusiasm of the participants and the overall high quality of discussions was a pleasant surprise.

2.5 Individual and group presentations: Since public speaking and presentations are an integral part of any group project - and an invaluable asset for an engineer- a number of opportunities were provided to the students to enhance the aforementioned skills. In addition to the impromptu presentations mentioned previously, each student was also responsible for an individual presentation on a topic relating to project management, leadership, engineering design, or an actual engineering project. The students were encouraged to make the presentations as interactive as possible and audience participation was rewarded.
This portion of the course provided for very interesting discussions, ranging from "merits of procrastination" to "comparison of leadership styles of George W. Bush and Bill Clinton". To provide the students with a chance to analyze their own presentations, each talk was recorded by a video camera, and the tape was provided to the presenter. The students were required to perform a selfevaluation of their talk, which proved to be extremely helpful in detecting the strengths and weaknesses of their public speaking abilities. At the conclusion of each semester, the teams were required to perform a group presentation, summarizing their design work and choices. In the $1^{\text {st }}$ semester, the teams were encouraged to "sell their ideas", while in the $2^{\text {nd }}$ semester, they were required to provide a thorough and qualitative description of their design (in a thesis defense format).

2.6 Logbooks: A standard engineering practice, logbooks were utilized in the interdisciplinary course for a variety of purposes. The logbooks were used for monitoring the progress of each team and the contribution of the group members, as well as providing a reference document for the teams. One of the major goals of this exercise was to allow students to practice documenting their design choices and ideas as a prelude to the requirements of the business world. During the $2^{\text {nd }}$ semester, the logbooks were examined on a weekly basis and the students showed vast improvement in their ability to record their progress concisely and accurately.

\section{Projects}

The following projects were undertaken in the interdisciplinary design course:

- Magnetically Levitated Train (MagLev): The team demonstrated proof of concept for levitation of a MagLev train. The test stand designed by the group enables the train to levitate with stability at various heights and corrects for mass disturbances.

- New Portable Locomotive System for an Outdoor Autonomous Rover: The team designed a portable robot that is capable of traversing different diameters pipes regardless of degree of inclination and can navigate through obstacles in pipes such as bends. The design can thus be used for pipeline inspection. It can also move over land in a variety of environments. 
- Portable Aerial Robotic Platform for Infrastructure Security: The team designed the prototype for an indoor, helicopter-like device that is capable of fully autonomous flight. The design can be used in situations where investigation of an indoor environment is deemed unsafe. The design can be fully customized by police officers and paramedics to suit different environments and can also eliminate the risks of entering hazardous surroundings.

- Power System Design in Developing Countries: A small demonstration model of a micro-hydro system was designed and implemented.

- Landmine Victim Rescue Vehicle: The project was to develop a new concept for a Landmine Rescue Vehicle. The key innovation of the design was the unique method of distributing the vehicle's weight given realistic terrain conditions.

- Harmonic Drive Servo (for LEGO robots): The team designed and implemented a novel harmonic drive from simple, off the shelf parts, allowing for easy reproduction by LEGO robotic researchers and enthusiasts.

- Solar Powered Security Network: The team designed and implemented a series of units that can store solar energy during the day, and use that energy to emit light once a security threat is detected at night. The units are also capable of communicating with each other.

- Solar Powered Car: The team was responsible for a comprehensive battery system including a battery case, cooling system, optimal cell arrangement, protection circuitry, and charge balancing circuitry for the University of Calgary's Solar Car.

- Surgical LEGO Robot: The team built a robot that is capable of scanning a $3 \mathrm{D}$ object, producing an accurate recreation of that object on a PC, and then returning to a specific point on the object as input by the user.

\section{Structure of groups}

There are 2 possible approaches to team structure and leadership that could have been taken in this course: assigning leadership roles and assigning leadership tasks.

There are a couple of problems with having a distinct team leader in these settings. First, all members of the team are equal in status $\left(4^{\text {th }}\right.$ year engineering students) hence the team leader wields no real authority over the rest of the team. Second, the imposed hierarchy will lead to unequal experiences for the team members.

In the alternative scenario, the leadership duties are shared among the team members. This format results in equal training of all team members as engineers, designers, and leaders.

Regardless of the leadership choice, the presence of a Faculty Advisor is critical for all groups. Supervising groups that work in the same area as their field of research (or interest), the faculty advisors can take on a number of roles, such as the project customer, consultant, mediator, etc. Since the faculty advisor position is not an officially recognized duty (at the University of Calgary), the interest and enthusiasm of the advisors is a necessity for these projects.

\section{Scheduling}

A major challenge with the interdisciplinary course was scheduling. The design course had to be coordinated with the courses from various departments. Since each department in the faculty of engineering schedules their own courses with no synchronization with their counterparts, finding a time slot for the course proved to be rather challenging. The problem was compounded by the fact that the students interested in the interdisciplinary design course were registered in a wide variety of elective courses in their final year of engineering.

The scheduling concerns were also evident in the difficulties the teams faced when organizing a common meeting or work times. It would be greatly beneficial to the students to schedule a common laboratory time that would ensure that all participants would have a convenient time to meet and work.

\section{Fairness of grading}

Apart from the scheduling and coordination difficulties, ensuring complete fairness in grading proved to be another challenge. The main problem arose from the fact that the faculty advisors had to be involved in the final grades for each project, which could have resulted in inconsistencies due to the different expectations, personalities, and many other factors. The solution to this problem was twofold: first, faculty advisors only recommended a final grade, which was subject to the instructor's approval. Second, only $15 \%$ of a student's final grade was assigned by the faculty advisors. All the other components of the course (reports, presentations, 
logbooks, quizzes, and exams) were marked by the course instructor or the teaching assistant in order to ensure consistency in grading.

\section{Equal distribution of work}

An inherent problem with the student design groups is the potential for unequal contributions by the team members. A consequent problem is ensuring that the entire team does not get penalized for the actions of a single member. A number of steps were taken to ensure that the design work was equally distributed among team members:

I) A team meeting was scheduled with the course instructor in fall and winter semesters, where the distribution of work was discussed, among many other topics. Any concerns and potential areas for problems were addressed, and every effort was made to ensure that all team members were made aware of their responsibilities.

II) To identify potential problems, a few surveys were included as part of the pop quizzes. In theses surveys, students were asked to indicate the amount of work performed by each member as a percentage of the total workload.

III)The faculty advisors were asked to assign an individual grade as well as team grade. Once again, a deterrent was put in place to discourage unequal contribution to the project.

IV) At the conclusion of each semester, an optional student team evaluation was performed. Teams that felt that their work was not distributed equally, had the option of evaluating their members' work. The students grade were only a recommendation to the course instructor, as it is strongly believed that students should not be able to directly manipulate a fellow student's grade. If a scenario occurred when a team was unhappy with the contributions of one of its members, the course instructor would investigate the complaint and penalize the member accordingly.

\section{Conclusions and recommendations}

This paper summarized some of the experiences from an interdisciplinary design course offered at the University of Calgary. The students' evaluation of the course and the instruction was extremely encouraging [10]. Most of the students found the experience of working in multi-disciplinary areas with peers from other departments to be very beneficial.

A number of elements in the course proved to be very positive and are highly recommended for future capstone design courses. The lecture format, as discussed previously, was very well received by the students. They also found the content to be directly applicable to their projects. Another positive experience was the conduct of design reviews. The students were very enthusiastic to learn about their colleagues' projects and ideas. Also, having students from one engineering department explain their work to students from another department presented an interesting challenge for the students in preparation for the workplace. The students also received a wealth of new ideas in these discussions. Weekly logbooks and self-evaluations of individual presentations were also very helpful to the students.

A number of recommendations can also be made to improve the course in the future. Considering the time limitations of $4^{\text {th }}$ year engineering students, the number of reports can be reduced to one per semester to allow for more design work. Also, coordinating the departmental course schedules and providing a planned laboratory time can help the students immensely. One of the concerns expressed by the students was the potential for predominantly mechanical or electrical oriented projects. Students can become overwhelmed or even discontented with the project if they feel that its requirements for the different disciplines are very unbalanced. This issue further emphasizes the important role of the faculty advisors. They have the ability to monitor and modify the project contents and requirements in order to create balance between the different disciplines.

\section{References}

[1] F. Hartman, Don't Park Your Brain Outside, Project Management Institute, Pennsylvania, 2000.

[2] J. Meredith, and S. Mantel, Project Management: A Managerial Approach, Wiley, 1995.

[3] H. Kerzner, Project Management: A Systems Approach to Planning, Scheduling, and Controlling, Wiley, 1998.

[4] J.F. Shtub, and S. Globerson, Project Management: Engineering, Technology, and Implementation, Prentice Hall, 1994.

[5] J. Gido, and J.P. Clements, Successful Project Management, ITP, 1999.

[6] R. Burke, Project Management: Planning and Control, Wiley, 1992.

[7] D.I. Cleland, K.M. Bursic, R. Puerzer, and Y. Vlasak, Project Management Casebook, Project Management Institute, 1998.

[8] K. Ulrich, and S. Eppiger, Product Design and Development, McGraw-Hill, 2004.

[9] J. Lewis, The Project Manager's Desk Reference, McGraw-Hill, 2000. 
[10] University of Calgary Universal Student Rating of Instruction, www.ucalgary.ca/VPA/usri/, May 2005. 